\title{
Bioaccumulation Due to Industrialization
}

loannis K Kalavrouziotis*

School of Science and Technology, Hellenic Open University, Greece

\section{Editor's Note}

The Journal of Environmental and analytical toxicology deals with the study of effects of natural and synthetic pollutants in the environment and with the determination of the levels of exposure to potential toxicants via air, water, soil and food. The current issue volume 6 , issue 3 envisaged the present status of pollution and the possible outcome.

Author Chebbi et al. aims to give an overview of the physicochemical quality of Produced Water (PW), located in the Bejaia Marine Terminal (BMT), which is discharged into the Mediterranean basin. This study uses the induced air flotation as an appropriate treatment process for the recovery of oil and more precisely of PAHs. Based on the results obtained, the present study reveals that the process followed the Higuchi model and all effluents were treated to reach neutral $\mathrm{pH}$, before being discharged into the sea [1].

In Ethiopia, due to rapid urbanization and industrialization, surface water imposed with large amount of pollutants. Author Gebre et al. conducted a cross-sectional study to assess water pollution along Modjo River where he chosen ten sampling sites based on wastewater discharge, accessibility and pollution feasibility of river water. Results found to be dumping the industrial wastewater into river, hence the authors recommend that National Environmental Quality Standard (NEQS) should be strictly enforced on industries to treat wastewater effectively [2].

The article of Hassan et al. investigated the bioaccumulation capability of jute mallow and their stress response to cadmium uptake, to be further used for phytoremediation. The results of this study showed that application of citric acid (CA) depressed $\mathrm{Cd}^{2+}$ uptake at all concentrations and jute mallow could possibly be a potential plant for phytoextraction of Cd without the use of CA as enhancer [3].

Developing any wastewater management strategy, a basic prequisite is to understand the quantum of organic loads in the wastewater. Dasgupta and Yildiz in their study, undertaken to assess $\mathrm{BOD}_{5}$ values of the wastewater generated from Morris County, USA suggested that the organic loads of the waters depend on the wastewater source. The industrial effluents exhibited the highest $\mathrm{BOD}_{5}$, while the pharmaceutical wastewaters showed the lowest values. However, they concluded that management of pharmaceutical and hospital wastewaters should be dealt with special care, owing to the possible occurrence of some harmful components or pathogens in such wastewaters [4].

\section{References}

1. Chebbi S, Belkacemi H, Merabet D (2016) Physicochemical Characterization and Kinetic Study of Flotation Process Applied to the Treatment of Produced Water. J Environ Anal Toxicol 6: 362.

2. Gebre AE, Demissie HF, Mengesha ST, Segni MT (2016) The Pollution Profile of Modjo River Due to Industrial Wastewater Discharge, in Modjo Town, Oromia, Ethiopia. J Environ Anal Toxicol 6: 363.

3. Hassan MS, Dagari MS, Babayo AU (2016) Effect of Citric Acid on Cadmium Ion Uptake and Stress Response of Hydroponically Grown Jute Mallow (Corchoruso litorius). J Environ Anal Toxicol 6: 375.

4. Dasgupta M, Yildiz Y (2016) Assessment of Biochemical Oxygen Demand as Indicator of Organic Load in Wastewaters of Morris County, New Jersey, USA. J Environ Anal Toxicol 6: 378. 